\title{
NARIZ ELECTRÓNICA INALÁMBRICA (NEI) PARA CONTROL DE EMISIONES DE GASES EN MINAS DE CARBÓN
}

\author{
WIRELESS ELECTRONIC NOSE (WEN) FOR GASES EMIS ION CONTROL IN \\ COAL MINES
}

MSc. Pablo Andrés Gomez Monsalve, PhD. Cristhian Manuel Durán Acevedo.

\author{
Universidad de Pamplona
}

Comité Editorial Revista Colombiana de Tecnologías de Avanzada

Ciudadela Universitaria. Pamplona, Norte de Santander, Colombia. Tel.: 57-7-5685303, Fax: 57-7-5685303, Ext. 144

E-mail: \{ingpablogomez@gmail.com, cmduran@unipamplona.edu.co \}

\begin{abstract}
This work describes a Wireless Electronic Nose (WEN) for the detection of different volatile compounds or toxic gases, generated in coal mines., in order to improve the safety of workers, the process operations and environment. The artificial multisensory system proposed in this study was developed through a set of six chemical gas sensors (MQ). The electronic device comprises of three main stages with different functions: The first stage, performs the sample acquisition, the second the measurement system and the third corresponds to the processing stage, which a computer with a flexible software provides different pattern recognition methods, such as: Principal Component Analysis (PCA), Principal Component Analysis with Kernels (PCAK) and Discriminant Function Analysis (DFA), where initially features extraction techniques were applied to the data set. The results obtained demonstrated the feasibility of the application, since the communication model, the programming algorithms and electronic implemented were sufficient to monitor and store the information of the sensor signals for the appropriate analysis. The success rate in the discrimination of measures was of $99 \%$, using pattern recognition methods.
\end{abstract}

Keywords: Electronic nose, Data acquisition, Toxic gases, ZigBee, Coal mines.

Resumen: Este trabajo describe una Nariz Electrónica Inalámbrica (NEI) para la detección de diferentes compuestos volátiles o gases tóxicos generados en minas de carbón, con el fin de mejorar la seguridad de los trabajadores, las operaciones del proceso y el medio ambiente. El sistema multisensorial artificial propuesto en este estudio se desarrolló a través de un conjunto de seis sensores de gases químicos (MQ).El dispositivo electrónico comprende tres etapas principales con diferentes funciones: La primera etapa, realiza la adquisición de la muestra, la segunda el sistema de medición y la tercera corresponde a la etapa de procesamiento, en la que un ordenador con un software flexible proporciona diferentes métodos de reconocimiento de patrones, como : Análisis de Componentes Principales (PCA), Análisis de Componentes Principales con Kernels (PCAK) y Análisis de Funciones Discriminantes (DFA), donde se aplicaron inicialmente técnicas de extracción de características al conjunto de datos. Los resultados obtenidos demostraron la viabilidad de la aplicación, ya que el modelo de comunicación, los algoritmos de programación y la implementación electrónica fueron suficientes para monitorizar y almacenar la información de las señales del sensor para el análisis adecuado. La tasa de éxito en la discriminación de las medidas fue del 99\%, utilizando métodos de reconocimiento de patrones

Palabras Claves: Nariz electrónica, Adquisición de datos, Gases tóxicos, ZigBee, Minas de carbón. 


\section{INTRODUCION}

Nowasdays the wireless communications systems for different industrial applications have an important advantages compared to a conventional wiring, which tend to increase the efficiency and safety in each of the processes. One of the main advantages that provide these types of systems is low cost of installation and maintenance, it is a work reported by (Chen et al, 2012).

Generally Industrial facilities are rigorous and costly beacuse they demanding in terms of quality of cabling requirements. Therefore, less cables means to use fewer elements in the system, especially when it comes to modernizing or upgrading components within the industry (Christin et al, 2010). For this reason, a wireless communication system can be a solution to be implemented in environments where required to install large amount of wiring lines, either for reasons of the location of the components or the same workplace (Mahmood et al., 2015)

Underground coal mines. At present, mining is a task that annually kills many lives because the vast majority of companies who do this work do not have detection methods to give safety for workers inside of a mine. Extreme security measures would avoid fatal accidents that year after year leave great human losses, material, social damage and a host of problems due to explosions and emissions of polluting gases.

In most cases, $95 \%$ of underground coal mines in Colombia does not have a system for detecting toxic gases in real time, as evidenced by experimental work (Restrepo et al, 2012). Usually mines periodically are controlled at different times during the work shift, using a measuring device. This equipment must have compliance certification, which refers that are explosion-proof and intrinsically safe to a fault under Ingress protection (IP 65 or higher).

Miners use instruments that cost about 3 to 4 thousand dollars, but must take it into dangerous places of the mine, so this does not guarantee the security of the person because suddenly a toxic gas may appear at any time during the excavation and quickly become a potentially dangerous environment that can generated an explosion with serious consequences. Colombia in recent years due to the lack of suitable methods to control and prevention of gas emissions and explosions there have been fatal accidents in places such as: Coal mine of San Fernando the most technologically advanced mine in the area, located in the municipality of Amaga (Antioquia, Colombia) in June 2010, where 73 miners died in an underground blast. Another case occurred in cave-in at an illegal coal mine in Colombia in village of Lenguazaque in central Colombia, leaving a total of 63 miners killed in the year 2011 where coal miners were killed by cause of explosions of gas methane, despite an increase in government regulations and safety inspections of the country. In the year 2012 forty one miners were confirmed dead due to the mine blast and carbon monoxide emissions in southwest China's Sichuan Province.

Toxic gases. Toxic gases in underground coal mines are those produced by the coalfield, but usually only introduced by exploitation. Table 1 illustrates the Permissible Limit Values (PLV) for polluting gases in any mine sector, where TLV-TWA (Threshold limit Value - Time Weighted Average) is the time weighted average concentration for an average 8 hour day and 40 hour workweek (Kumar et at, 2013).

Regarding TLV-STEL (Threshold Limit Value Short-Term Exposure Limit) is the concentration to which workers can be exposed continuously for a short period of time (i.e., A period no more than 15 minutes with a period of at least 60 minutes between two exposures at this level and no more than four times during the workday) without suffering health problems such as: Irritation, chronic or irreversible damage, narcosis, etc) (Ministerio de Minas y Energía (Decreto 1886), 2015).

Table 1: Permissible limit values (PLV) of polluting gases

\begin{tabular}{|c|c|c|c|}
\hline Toxic gases & Nomenclature & $\begin{array}{l}\text { TLV- } \\
\text { TWA } \\
\text { (ppm) }\end{array}$ & $\begin{array}{l}\text { TLV- } \\
\text { STEL } \\
\text { (ppm) }\end{array}$ \\
\hline $\begin{array}{l}\text { Carbon } \\
\text { Dioxide }\end{array}$ & $\mathrm{CO} 2$ & 5000 & 30000 \\
\hline $\begin{array}{l}\text { Carbon } \\
\text { Monoxide }\end{array}$ & $\mathrm{CO}$ & 25 & - \\
\hline $\begin{array}{l}\text { Hydrogen } \\
\text { Sulfide }\end{array}$ & $\mathrm{H} 2 \mathrm{~S}$ & 1 & 5 \\
\hline $\begin{array}{l}\text { Sulfur } \\
\text { Anhydride }\end{array}$ & $\mathrm{SO} 2$ & - & 0.25 \\
\hline Nitric Oxide & $\mathrm{NO}$ & 25 & - \\
\hline $\begin{array}{l}\text { Nitrogen } \\
\text { Dioxide }\end{array}$ & $\mathrm{NO} 2$ & 0.2 & - \\
\hline
\end{tabular}

Gas monitoring

Inside the underground coal mines is necessary to implement a permanent and continuous monitoring of methane $(\mathrm{CH} 4)$ and oxygen gases in transport and ventilation routes (Fakundu et al, 
2014). Also where have active fire outbreaks must be implemented a system of permanent and continuous monitoring of carbon monoxide $(\mathrm{CO})$ and oxygen (O2). These gases should be monitors continuously and permanently in places where vehicles are used with internal combustion engine. Before each use of the measuring equipment, it must make a clear verification of the range ( $\pm 10 \%$ standard value of the pattern).

In this study were implemented some XBee wireless modules for communication between nodes in a gas sensor array, which are important part of the development of an electronic nose in order to detect toxic gases usually generated in coal mines. The results were satisfactory, since it gives a wide range of possibilities to be implemented in different industrial processes, environmental control (measuring quality air), health sectors, etc.

\subsection{Electronic Nose (e-nose)}

Electronic nose is defined as a measurement instrument that comprises of a chemical gas sensors and diverse pattern recognition methods able to recognize simples and complex odours (Durán, 2008).

Gas detection systems have many limitations due to the design based on the interpretation of a dominant signal from a sensor, where the sensitivity is oriented to a type of gas or gases in particular identifying only some types.

An example for it, a gas detector which respond only in the presence of methane gas where the action is given to active an alarm which indicates the presence of gas, showing the concentration as well, but cannot indicate whether this gas it comes from a natural gas source or any mixture.

In addition, some systems are only designed to detect methane and no other gases. Regarding this situation, electronic noses can overcome this limitation, because the processing is based on a human-like nose, where the interpretation of the signals is a data set which can recognize Volatiles Organics Compounds (VOC's) so like the possibility to learn to identify a set of new smells.

\subsubsection{Comparison between the electronic nose and the human olfactory system}

Figure 1 shows a comparison between the components that make up the biological versus artificial olfaction system and the similarities of each of the processes to be performed for the detection of an aroma.

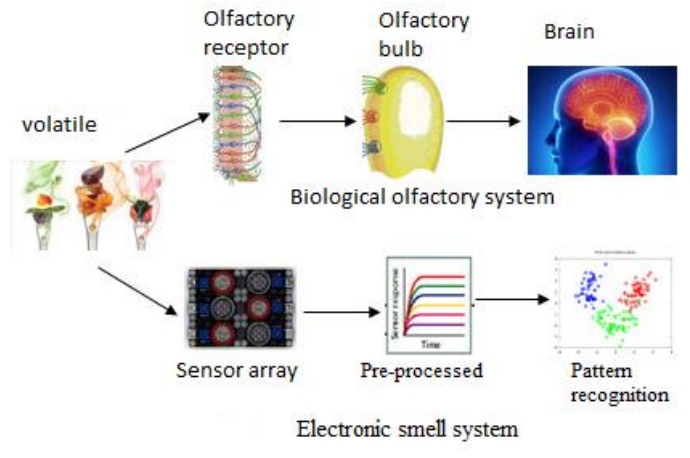

Fig. 1. Comparis on between the structure of the Biological Smell and the Electronic Smell systems

Olfactory receptors are represented by a group of sensors (sensor array) which produce an electrical signal depending on the type of aroma detected. The olfactory bulb receives these signals and then sends them to the brain through the nerves, much like the pre-processing techniques, they prepare the signals by reducing the volume of information and minimizing the noise and drifts introduced by the chemoreceptors. Pattern recognition methods perform functions equivalent to those performed in the cortex of the brain, the final stage of the human olfactory process, where the different aromas learned over time are identified, classified, interpreted and memorized. (Durán, 2008).

\subsubsection{Stages and working sequence of a standard electronic nose}

The most important thing for an electronic nose is to take a sample of some type of aroma or gaseous sample and to be able to identify it, classify it and / or quantify it. This means that an electronic nose is made up of several stages.

Figure 2 shows the typical work sequence and the main stages involved in the analysis of aromas using an electronic olfactory system.

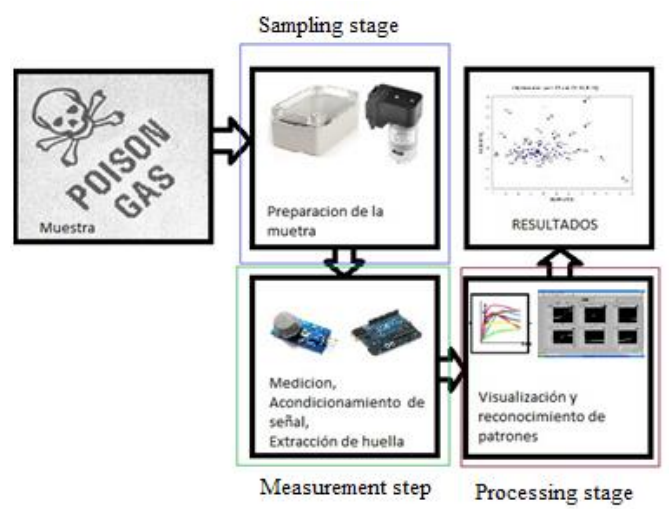

Fig. 2. Sequence for aroma analys is 
Sampling stage: The sample is taken and sent to the place where the measurement is to be carried out, which is mainly made up of a hermetically sealed chamber and the elements that carry the sample.

Measurement step: It is composed of the gas sensors and a data acquisition device. At this stage the sensors generally give a typical response that represents the measurement of the change of some physical parameter. Example, resistance or conductivity. Response times range from seconds to minutes, and their value changes according to the stimulus received from the aromatic compounds in the sample.

Processing stage: Each sensor will then give a characteristic response of the sample, obtaining in the end a data matrix of $m$ columns per $n$ rows, where the columns will be the number of sensors present in the nose and $n$ the number of samples taken. This information is processed by the equipment designed to identify the odor (computer or embedded equipment), using pattern recognition techniques.(Durán, 2005)

ZigBee communication protocol ZigBee technology is basically a wireless communications protocol based on the communication standard for wireless networks under the standard IEEE_802.15.4 (Baronti et al, 2007). It is very useful to develop sensor networks in environments such as: Industry, medical, mining, environment, etc, where communications are performed in the range of $2.4 \mathrm{GHz}$. ZigBee network provides the following communication: A single coordinator, one or more routers and one or more end mobile devices. This type of features can be configured in a commercial XBee device. Different wireless technologies (i.e., ZigBee, Bluetooth and $\mathrm{WiFi}$ standards), and most popular standards share the 2.4 GHz unlicensed band. (Gomez \& Durán, 2015)

It may be used as a guide to decide which technology could be better for any application. It is very important to know the differences in terms of performance, low cost, portability, speed, memory capacity and topologies. Bluetooth and ZigBee technologies have currents similar transmission, but in standby state is possible to save electrical energy with ZigBee in comparison to Bluetooth, where should continue sending information frequently to maintain the synchronization which cannot easily enter to sleep mode.

\subsubsection{ZigBee Network Topologies}

In the case of ZigBee networks, there is no Physical distribution of components, if not a Logical connection between nodes of the network. This type of Logical connections are: Pair or Point Point.

Star.

Mesh.

Cluster Tree.

Figure 3 illustrates the distribution of each of The logical topologies of ZigBee network

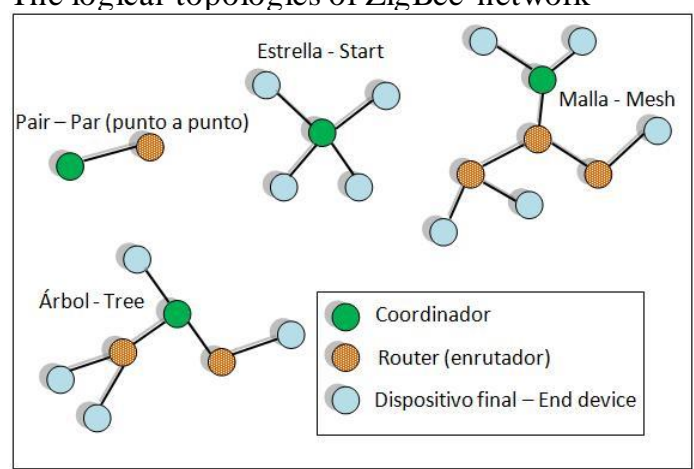

Fig. 3. Logical network topologies(Gomez \& Durán, 2015).

\section{MATERIALS AND METHODS}

The following section presents the components used for the design and development of multisensory prototype. The prototype consists basically of a sampling and measurement system and comprises of a set of metal oxide gas sensors (Type MQ, see Table 2) with 6 units and a data processing stage used to classify a set of acquired samples by data acquisition card wirelessly. MQ sensors were used due to the low cost, versatility and wide range of volatiles detection, helping to identify gases in coal mines in different concentrations.

Table 2: MQ Sensors

\begin{tabular}{ll}
\hline Sensor & Target gases \\
\hline MQ-2 & $\begin{array}{l}\text { LP gas, I-butane, propane, } \\
\text { methane, alcohol, hydrogen, } \\
\text { smoke. }\end{array}$ \\
MQ-3 & Alcohol, ethanol \\
MQ-6 & LP gas and butane \\
MQ-7 & Carbon Monoxide \\
MQ-8 & Hydrogen \\
MQ-9 & Carbon Monoxide and fuel gas
\end{tabular}

The Figure 4 shows the electronic nose system (part a) with the design of the sensors chamber (part b) and two vacuum pumps (for sample acquisition) located within of a methacrylate box, in order to extract the toxic gas sample and develop the purge of the measuring chamber. 


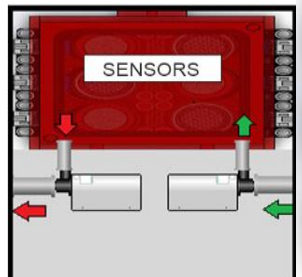

(a)

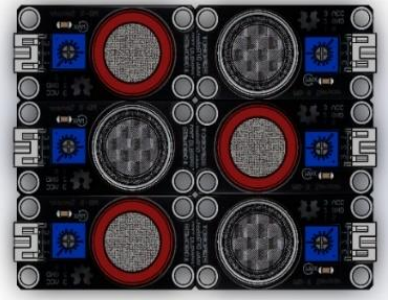

(b)
Fig. 4. a) General diagram of the measurement systemb) MQ Gas sensors (Layout PCB)

The wireless technology used in this study was ZigBee, which is a communications protocol that can use a single coordinator, one or more routers and various mobile devices (i.e., e-noses). This type of features can be configured in an XBee module. An Arduino UNO card for data acquisition was implemented to sensory system, where the main features taken into account were. Low energy consumption, low cost, in addition to its versatility and compatibility with various sensors and communication modules in 802.15.4 platform.

\subsection{Communication Model}

The topology of the wireless communication system is a tree-like structure, which can be used in confined spaces. For this reason, it is possible to implement the distribution of an electronic nose within a location with limited space, such as a coal mine or indoor environments. In turn, it is possible to obtain better communication between nodes of the same type, as shown in Figure 5. The model was implemented with a standard configuration API (Application Programming Interface), which allows more information node and thus know the status of it. The data or frame is transmitted in serial mode to the coordinator (C), which is interconnected to a Xbee-USB-PC adapter, to send reques ts to the present node and handles this request depending on the case (i.e., routers or e-noses $(1,2$ or 3 ). If an end-device (3) were selected, this will indicate a default router which will serve as a repeater for that coordinator receives data from the remote point.

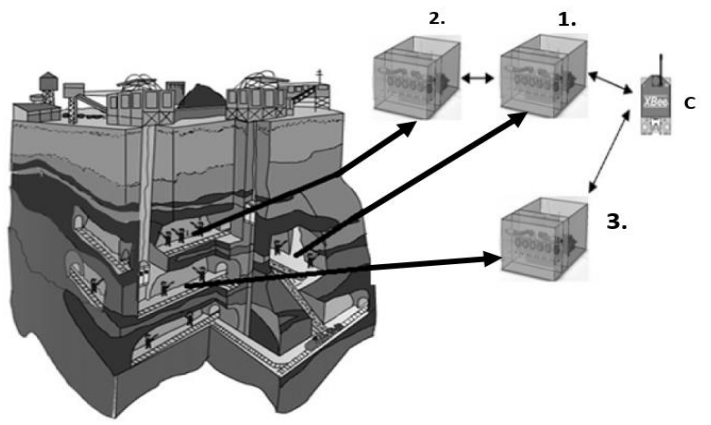

Fig. 5. Communication model (locations of the nodes within of a mine).

\subsection{Data Processing methods}

A number of 32 samples were acquired with the sensory system from toxic gas cylinders, where 8 samples were collected for each category with a specific colour in order to perform the analysis and validation of the system (see Table 3 ). Figures 6, 7, 8 and 9 show the result obtained from one of the samples obtained from each cylinder of the sensor array, each color of the lines represents the response of the Sensors individually, the results obtained are in voltage levels.

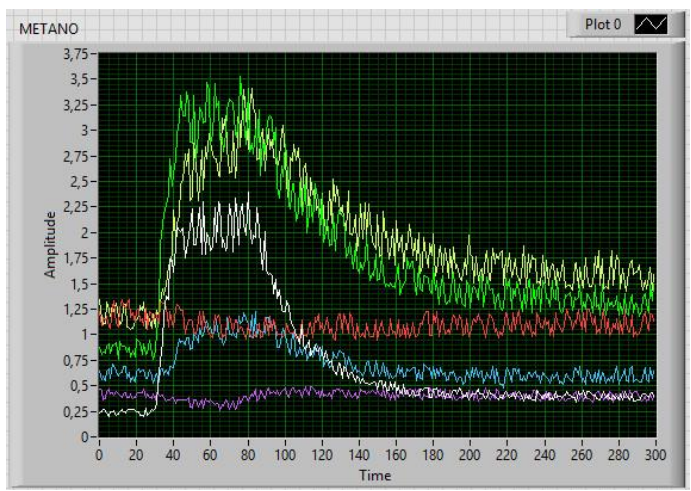

Fig. 6. Response of the sensor array to the methane cylinder sample.

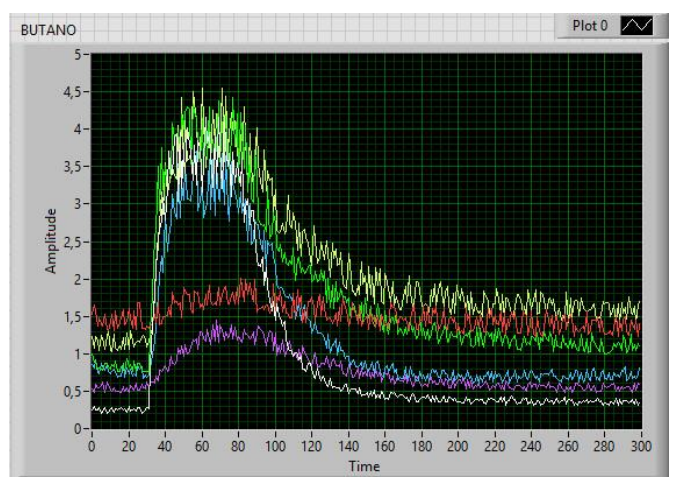

Fig. 7. Response of the sensor array to the butane cylinder sample.

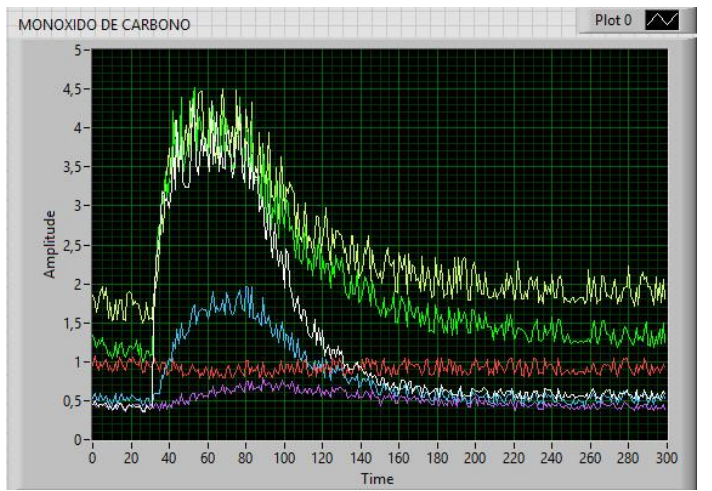

Fig. 8. Response of the array of sensors to the sample of the carbon monoxide cylinder. 


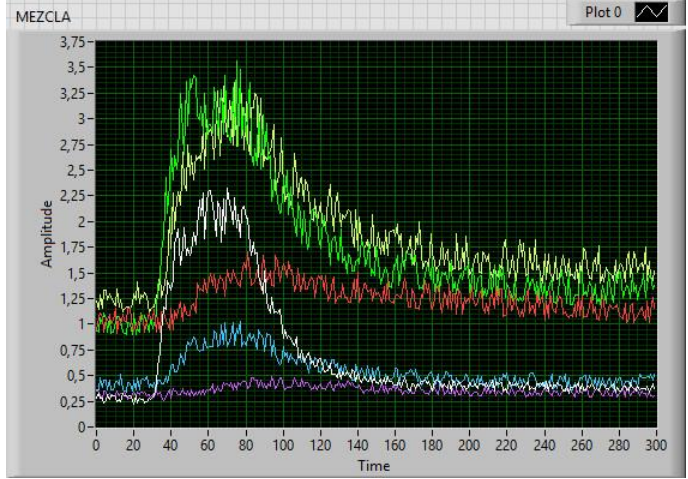

Fig. 9. Response of the sensor array to the cylinder sample with the gas mixture

The data set were pre-processed using a feature extraction technique such as absolute fractional differences - maximum logarithm, $\mathrm{Eq}(1)$, to obtain the discrimination of the data. After that, the normalized data were processed through applying pattern recognition methods such as Principal Components Analysis (PCA), Principal Component Analysis with Kernels (PCAK) and Discriminant Function Analysis (DFA).(Durán, Jaimes, \& Gualdrón, 2016)

$$
\log \left(\frac{(G \max -G \min )}{G \max }\right)
$$

Where, Gmax is the response or the maximum conductance (resistance inverse) of the sensors in presence of odour, and Gmin is the steady-state of minimum conductance or baseline signal. Once trained the system, a new measure (X) was acquired randomly through the cylinders in order to discriminate which class belongs.

Table.3 Identification of categories

\begin{tabular}{llll}
\hline $\begin{array}{l}\text { Gas } \\
\text { cylinders }\end{array}$ & Compound & Category & Colour \\
\hline 1 & Propane, butane0 & Red \\
2 & Methane(CH4) & 1 & green \\
3 & Carbon & 2 & Blue \\
& monoxide(CO) & \\
4 & Mixed gas & 3 & Yellow \\
5 & Other & 4 & Purple \\
& (X symbol & \\
& $\begin{array}{l}\text { represents } \\
\text { a new gas) }\end{array}$ & \\
&
\end{tabular}

\section{RESULTS AND DISCUSSION}

Figure 10 illustrate the wireless electronic nose prototype which was developed in order to be applied previously in indoor environments but with alternative to cover a wide range of applications, in this case was applied in underground coal mines. The data pre-processing and processing algorithms were done with tools provided by Labview having added a Graphical User Interface (GUI).

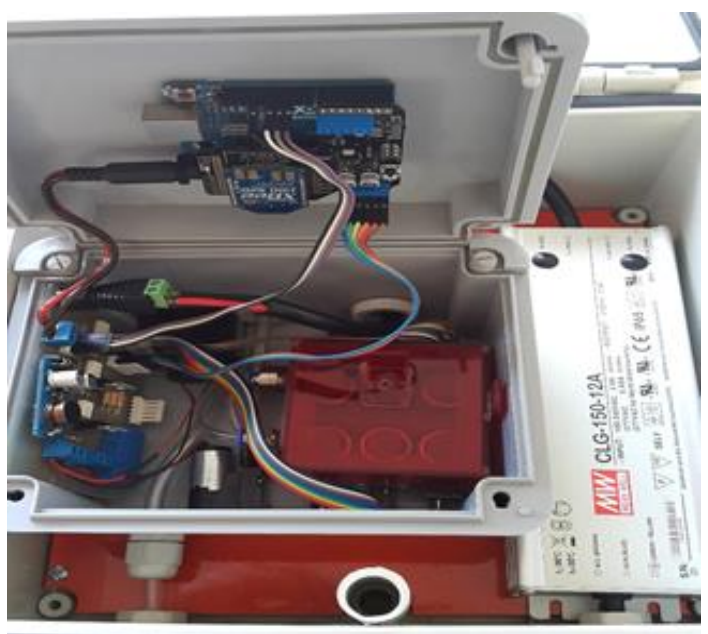

Fig. 10. WEN Prototype

Figure 11 depicts the classification realized with the PCA and identification of groups could be observed in detail. PCA was selected in this application because is an effective unsupervised linear method to project data from several sensors to a two-dimensional plane and it is possible to discriminate easily the data set as well.(Rios, Durán, \& Cuenca, 2014)

It is important to clarify that both PCA and DFA were used by being linear supervised and unsupervised methods to project data set from different sensors to a two-dimensional plane (Martinez A.M., Kak A, 2001).

The clusters of CO (Blue colour) and Methane (Red colour) compounds are very close, so this could have some overlaps with samples near these two groups. Anyway a new sample of carbon monoxide gas was conducted, where it was possible to determine that this new measure is similar to the group of the 32 measures, therefore was possible to identify this sample correctly. The figure shows the first two principal components represented in $98.30 \%$ of the variance in the data set.

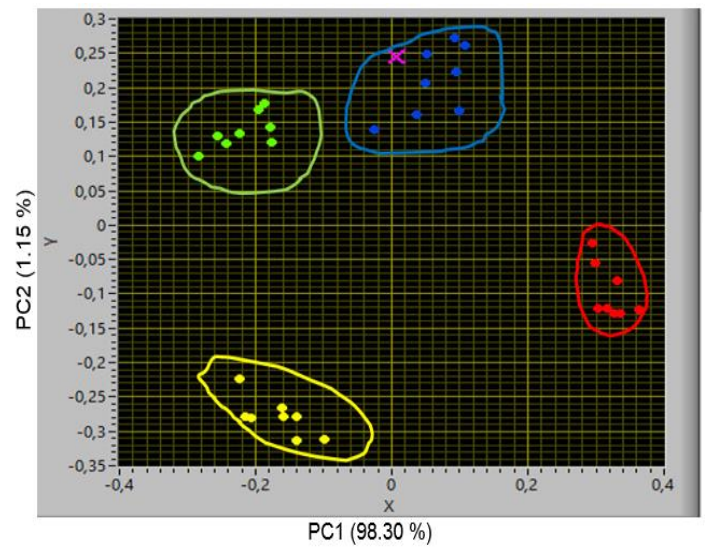

Fig. 11. PCA obtained with statical parameter $(\log ((|\operatorname{Gmax}-\mathrm{Gmin}|) / \mathrm{Gmax}))$ 
The Principal Component Analysis with Kernels (PCAK) is an extension of the Principal Component Analysis (PCA). PCAK is basically an PCA on the original data after they were sent, via a non-linear transformation, to a Hilbert space of high dimension. The key for a successful PCAK is to extract directions of maximum variability in the data transformed space and then identify these directions with patterns of maximum variability of the original data.(Montano, 2013)

Figure 12 depicts the classification realized with the PCAK and identification of groups could be observed in detail. The type of kernel used was polynomial

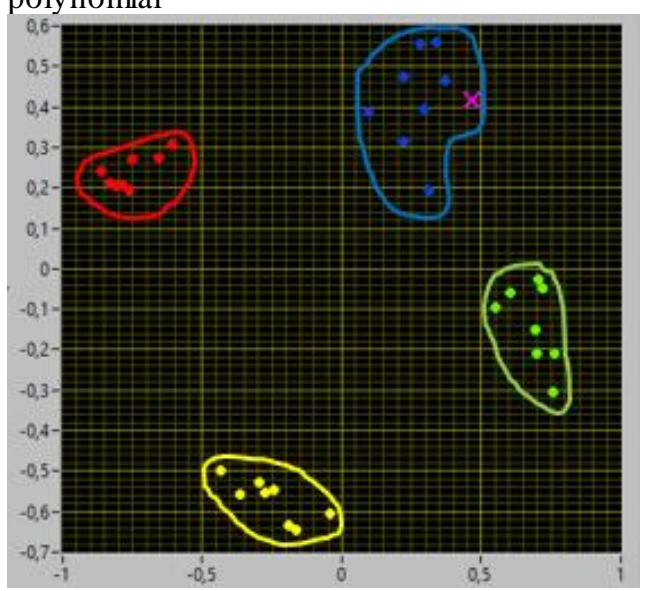

Fig. 12. PCAK obtained with statical parameter $(\log ((|\mathrm{Gmax}-\mathrm{Gmin}|) / \mathrm{Gmax}))$

The DFA technique was applied in this study to discriminate the groups or clusters, to define the better way to separate groups and to remove variables which are little related to group distinctions. Therefore, a number of two latent variable (factors) of a linear combination of independent variables were chosen.

Figure 13 illustrates the results of DFA were obtained from four categories with 32 measurements mentioned above, where the new measure of carbon monoxide $(\mathrm{X})$ was classified correctly within carbon monoxide cluster. It was observed that the distance between the different groups showed good discrimination, achieving an adequate selectivity and repeatability of the system and demonstrating a high performance of the equipment. In addition, this analys is showed that DFA is a good supervised method to distinguish different varieties of toxic gases presents in underground coal mines. The two first functions achieved up $99 \%$ of variance in the data set.

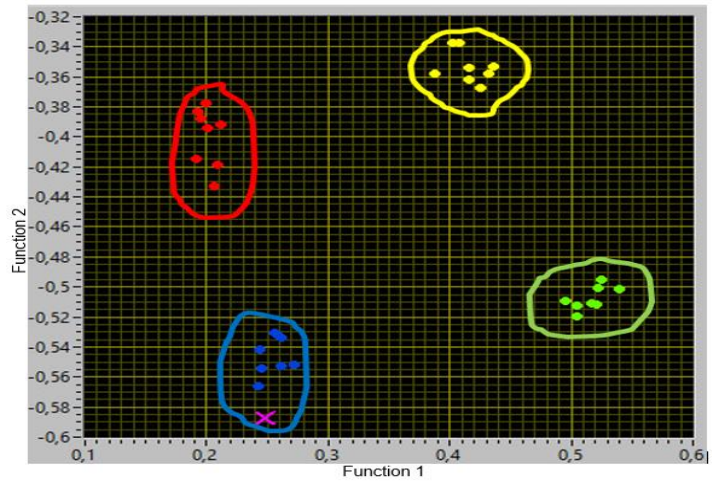

Fig. 13. DFA obtained with statical parameter $(\log ((|G \max -G \min |) / G \max ))$

\section{CONCLUS IONS}

The sensitivity and selectivity obtained by the WEN system was good, and the repeatability shown by the equipment was satisfactory. The enose developed on a ZigBee wireless network shows the viability to implement a measurement instrument to detect VOCs in Indoor Environments (Underground Coal Mines) due to low-power consumption, reliability and high portability.

Through the results obtained with the WEN is possible to develop real-time applications for monitoring and control of various processes, requiring a multisensory system of such characteristics to be implemented in different sectors (e.g, industrial sector, environmental, health, etc).The pattern recognition methods were implemented on the normalized response matrix, where the two first discriminant factors or scores reached more than $99 \%$ of variance in the data.

The data processing with pattern recognition methods was successful but in the different experiments showed better response DFA in comparis on to PCA.

\section{ACKNOWLEDGMENTS}

We would like to give our most sincere thanks to the Pamplona University by funding an important part of this project. 


\section{REFERENCES}

Chen S., Yao J., Wu Y., 2012, Analysis of the Power Consumption for Wireless Sensor Network Node Based on Zigbee, Procedia, Engineering, 29, 1994-1998.

Christin D., P Mogre., Hollick M., 2010, Survey on Wireless Sensor Network Technologies for Industrial Automation: The Security and Quality of Service Perspectives, Future Internet, 2(2), 96-125, doi:10.3390/fi2020096.

Durán A.C.M., Rodríguez J.C., 2008, Sistema de Olfato Electrónico para la Detección de compuestos Volátiles. Revista colombiana de tecnologías de Avanzada, 12, 20-26.

Durán, C., Jaimes, A., \& Gualdrón, O. (2016). APPLICATION OF ELECTRONIC TONGUE FOR CLASSIFICATION OF WINES. Revista Colombiana de Tecnologías de Avanzada, 28-(692-7257), 16-21.

Durán C. M. A. (2005). Diseño y optimización de los subsistemas de un sistema de olfato electrónico para aplicaciones agroalimentarias $e$ industria. Universitat Rovira I Virgili.

Gomez, P., \& Durán, C. (2015). Data acquisition from an array of gas sensors (e-nose), through xbee communications modules. Revista Colombiana de Tecnologías de Avanzada, 26(1692-7257), 68-73.

Montano, J. A. (2013). Análisis de componentes principales con Kernels: Una propuesta de mejora del Kernel. universidad veracruzana.

Rios, Y., Durán, C., \& Cuenca, M. (2014). MEADS DISCRIMINATION THROUGH AN ELECTRONIC TONGUE. Revista Colombiana de Tecnologías de Avanzada, 23(1692-7257-), 1-8.

Mahmood A., Nadeem J., Razzaq S., 2015, A review of wireless communications for smart grid, Review Article Renewable and Sustainable Energy Reviews, 41, 248-260.

Restrepo-Echeverri D., Ríos-Cano S., JiménezBuiles J., (2012). Detección y control de atmósferas explosivas en minas subterráneas de carbón usando programación estructurada, Revista Educación en Ingeniería, 7, 10-21.

Kumar T.M.G., Kingson R.P., Verma A., Kumar R., Mandal S., Dutta S.K., Chaulya and Prasad G.M., 2013, Applications of Gas Monitoring Sensors in Underground Coal Mines and Hazardous Areas, Inter Journ of Comp. Tech. and Elec. Engi, 3(3), 915.

Ministerio de Minas y Energía Colombia (Decreto 1886), 2015, <www.anm.gov.co/>, accessed 22.03.2016

Fakundu B., Andrews G.E., Phylaktou H.N., 2014, Gas Explosion Venting: Comparison of Square and Circular Vents, Chemical Engineering Transactions, 36, 163-168, DOI: 10.3303/CET 1436028

Baronti P., Pillai P., Chook W. V., Chessa S., Gotta A., Hu Y., 2007, Wireless sensor networks: A survey on the state of the art and the 802.15.4 and zigBee standards, Computer Communications, 30, 16551695

Martinez A.M., Kak A., 2001, PCA versus LDA, IEEE transactions on pattern analysis and machine intelligence, 23(2), 228-233. DOI:10.1109/34.908974. 